\title{
Sobre o feminismo decolonial
}

On Decolonial Feminism

\author{
Lívia Santos de Souza ${ }^{1}$ (iD) 0000-0003-4406-5415
}

'Universidade Federal da Integração Latino-Americana, Centro Interdisciplinar de Letras e Artes, Foz do Iguaçu, PR, Brasil. 85866-000 - coordenacao.cila@unila.edu.br

\section{$-7$}

\author{
HOLLANDA, Heloísa Buarque de (org.). \\ Pensamento Feminista Hoje: Perspectivas Decoloniais. \\ Rio de Janeiro: Bazar do Tempo, 2020. 381 p.
}

\begin{abstract}
A terceira obra da série Pensamento Feminista, organizada por Heloísa Buarque de Hollanda (2020), reúne alguns textos fundamentais para a compreensão do feminismo a partir da perspectiva decolonial, uma das vertentes teórico-epistemológicas que mais tem ganhado espaço nos estudos latino-americanos hoje. Essa abordagem direcionada é o grande trunfo do volume, já que consegue garantir a coesão interna do livro e estimular reflexões de grande relevância para as diversas áreas do conhecimento que dialogam com os estudos feministas hoje.

O texto de abertura assinado pela organizadora introduz de forma muito adequada o volume, apresentando as partes que o compõem e fazendo uma breve apresentação histórica do que foi o chamado giro decolonial. Ao mesmo tempo, em sua introdução, Heloísa lida com a urgência das questões que o feminismo decolonial coloca: "Como construir um feminismo sem levar em conta as perspectivas originárias? Sem absorver as gramáticas das lutas e dos levantes emancipatórios que acompanham nossas histórias? Como podemos reconsiderar as fontes e conceitos do feminismo ocidental?" (Heloísa Buarque de HOLLANDA, 2020, p. 12), são perguntas feitas pela autora ainda nesse trecho inicial e que serão respondidas de diversas formas - e por vozes igualmente diversas - ao longo das 380 páginas do livro.

O volume está organizado em três partes, "Desafiando Matrizes", "Práticas Decoloniais" e "Outras Línguas: Três artistas brasileiras", de modo a fazer um recorte bastante abrangente, tanto temporal quanto geográfico, do chamado feminismo decolonial. Há desde textos do fim da década de 1980, como "Por um Feminismo-Afro-Latino-Americano" de Lélia Gonzalez, até textos publicados pela primeira vez em 2019, como "Fazendo uma genealogia da experiência" de Yuderkis Espinosa Miñoso.
\end{abstract}

Os oito textos que compõem a primeira parte do livro têm origens bastante distintas, três autoras do Brasil, duas da República Dominicana, uma da Argentina, uma da Argélia e uma da Nigéria. Nessa primeira seção acessamos alguns dos textos mais paradigmáticos para os estudos de gênero que dialogam com a perspectiva colonial: "Colonialidade e gênero", escrito por María Lugones é talvez o nome mais representativo nesse sentido. Nesse texto a autora parte da noção de colonialidade de Quijano para, embora reconhecendo toda a relevância do trabalho do intelectual peruano, evidenciar as limitações de suas considerações sobre a colonialidade de gênero. Lugones, então, reitera a situação de apagamento que das mulheres colonizadas no discurso capitalista eurocêntrico.

Outro capítulo fundamental da primeira parte do livro é "Por um feminismo afro-latinoamericano" de Lélia Gonzalez. A inclusão desse texto, especialmente inovador para o contexto de 
sua publicação em 1988, é significativa para o reconhecimento do pioneirismo de Lélia Gonzalez, já que trata da intercessão entre racismo e feminismo a partir da realidade latino-americana décadas antes que esse movimento seja feito por outras intelectuais no continente. Ao ler as muitíssimo atuais considerações de González sobre a relação entre capitalismo, racismo e opressão das mulheres amefricanas e ameríndias, não restam dúvidas sobre a afinidade de suas ideias com a perspectiva decolonial.

Merecem destaque também os textos escritos por autoras africanas incluídos nessa primeira seção, "Decolonizando o Feminismo (mulheres argelinas em questão)", da argelina Marnia lazreg, e "Conceituando o Gênero: os fundamentos eurocêntricos dos conceitos feministas e o desafio das epistemologias africanas", da nigeriana Oyèronké Oyìwùmí. Ambos são excelentes mostras de como a ruptura com epistemologias hegemônicas - que marca o chamado giro decolonial - tem grande força no pensamento africano contemporâneo. Lazreg nos convida a repensar a validade da categoria mulher árabe como um bloco homogêneo e oprimido pela religião e a ressignificar símbolos dessa redução como o véu. Oyìuùmí, que é citada no texto de Lugones, desconstrói com maestria a naturalidade do conceito ocidental de família generificada, demonstrando como as noções tradicionalmente universalizadas de patriarcado e gênero não fazem sentido na realidade iorubá tradicional.

Os capítulos "Fazendo uma genealogia da experiência: o método rumo a uma crítica da colonialidade da razão feminista a partir da experiência histórica da América Latina" e "Construindo metodologias feministas a partir do feminismo decolonial" escritos pelas autoras dominicanas Yuderkys Espinosa Miñoso e Ochy Curiel, respectivamente, apresentam um interessante ponto comum: ambas enfatizam a necessidade de ruptura com determinados valores do chamado feminismo ocidental. Espinosa Miñoso não hesita em criticar o feminismo latino-americano que sempre buscou se encaixar nos padrões determinados pelo pensamento eurocêntrico e reivindica abertamente um feminismo que parta da experiência latino-americana. Em profunda sintonia com o texto de sua conterrânea, Curiel demanda o desenvolvimento de metodologias adequadas ao contexto latino-americano.

A necessidade de questionamento dos feminismos eurocêntricos e do desenvolvimento de novas epistemologias a partir do sul também move os textos escritos pelas brasileiras Susana de Castro e Suely Aldir Messeder: "Condescendência: estratégia pater-colonial de poder" e "A pesquisadora encarnada: uma trajetória decolonial na construção do saber científico blasfêmico". No primeiro, a professora/pesquisadora faz um recorrido histórico no pensamento decolonial em relação às questões de gênero, passando por vários dos nomes que integram o livro, como María Lugones e Yuderkis Espinosa Miñoso. O texto de Messeder trata de questões bastante semelhantes, embora adote uma perspectiva bastante distinta. A autora reflete a partir de sua experiência com o trabalho etnográfico para evidenciar também a necessidade de se mudar a forma como o saber científico é construído.

Destaco também nessa primeira parte a ausência de um nome que me parece fundamental para a reflexão sobre pensamento feminista e decolonialidade: Gloria Anzaldúa. A célebre autora de origem chicana aparece em Pensamento Feminista: conceitos fundamentais (2019) - primeiro volume da coleção -, assim como María Lugones, mas diferente da professora argentina, não tem um novo texto publicado em Perspectivas Decoloniais. Muito pouco da obra de Anzaldúa está traduzido para o português e, sem dúvidas, muitos de seus textos apresentam uma afinidade inquestionável com essa coletânea organizada por Heloísa Buarque de Hollanda.

A segunda parte do livro, denominada "Práticas Decoloniais" reúne outros oito textos que, desde pontos de vista bastante distintos entre si, buscam pensar questões como os direitos humanos, o movimento ambiental e a tradução a partir do feminismo decolonial. São textos que em certos momentos desafiam a própria tradição da escrita acadêmica tradicional. Em "Uma ruptura epistemológica com o feminismo ocidental", Julieta Paredes Carvajal apresenta o feminismo comunitário com base na organização familiar tradicional andina em um texto que mescla diagramas, listas, entre outros elementos gráficos pouco usuais em textos acadêmicos das ciências humanas.

Outro texto a desafiar as formas acadêmicas tradicionais é "Carta de uma ex-mulata a Judith Butler" escrito por Angela Figueiredo. A autora adota um gênero dialógico, a carta, para reposicionar alguns dos conceitos de Butler na realidade brasileira. "Muros e pontes no horizonte da prática feminista: uma reflexão", de Maria Elvira Díaz Benítez, também nessa segunda parte do livro, trata da interseccionalidade em perspectiva decolonial para pensar o feminismo latinoamericano hoje. Seguindo essa mesma linha, em "Nossos feminismos revisitados", Luiza Bairros explicita a necessidade de transformação de conceitos fundamentais para o feminismo para que esse possa efetivamente incluir a mulher negra.

"Pensar a partir do feminismo: críticas e alternativas ao desenvolvimento" escrito por Alba margarita Aguinaga Barragán, Miriam Lang, Dunia Mokrani Chávez e Alejandra Santillana parte de um debate fundamental para os feminismos não-hegemônicos, mas frequentemente 
negligenciado: a economia. Ao tecer uma crítica ao desenvolvimentismo que caracterizou economicamente o colonialismo no sul global, incluindo o machismo como elemento ideológico fundamental, as autoras conseguem estabelecer uma extremamente necessária associação entre capitalismo, colonialismo e opressão de gênero. Trazendo à tona temas como economia feminista e economia do cuidado, o texto monta um panorama abrangente e propositivo das principais reflexões atuais sobre feminismo e desenvolvimento.

Maria da Graça Costa, autora de "Agroecologia, ecofeminismos e bem viver: emergências Decoloniais no movimento ambientalista brasileiro", e Thula Rafaela de Oliveira Pires, com "Por uma noção amefricana de Direitos Humanos", têm em comum - embora tratem de temas aparentemente distantes entre si - seu esforço de denúncia de categorias vistas pelo conhecimento hegemônico como universais, tais quais preservação ambiental e direitos humanos. Ambas as autoras refletem sobre os impactos das questões de gênero e raça para o tratamento desses assuntos, absolutamente relevantes na contemporaneidade.

No último texto dessa segunda parte, "Feminismos Decoloniais e a política e a ética da tradução", Claudia de Lima Costa parte da leitura e da releitura de uma pintura de Manet para refletir sobre a importância da tradução não só como movimento linguístico, mas também como um exercício-chave para a formação das epistemologias feministas decoloniais. Sem dúvidas, esse é um capítulo fundamental para pensar as contribuições do feminismo decolonial para a crítica artística.

A terceira e última parte reúne reproduções de obras de três artistas plásticas, Adriana Varejão, Rosana Paulino e Marcela Cantuária. Trata-se de uma seção que trabalha questões evidenciadas nos textos teóricos, a partir de outras linguagens. Varejão, ao utilizar elementos tradicionais da estética colonial portuguesa - como os azulejos e técnicas de pintura que remetem ao século XVII -, representa a violência do colonizador em relação às mulheres dos povos originários e escravizados, com grande destaque para a violência sexual. Isso se dá tanto a partir da representação gráfica, em quadros que incluem a representação de um padre português em pleno ato sexual com uma mulher escravizada quanto através de intervenções nessas mesmas obras, as telas de Varejão têm fendas, cortes que remetem simultaneamente à brutalidade das ações e à vagina.

As obras de Rosana Paulino e Marcela Cantuária, embora utilizem suportes visuais muito distintos, a primeira compõe instalações que se utilizam principalmente de elementos têxteis como bastidores para bordados e patuás; já a segunda artista trabalha com pintura. Ambas têm em comum a defesa de um feminismo indissociável das questões raciais, de classe e do meio ambiente. Entre as obras reproduzidas no livro, "Bastidores", de Paulino, traz fotos de mulheres negras com costuras que cobrem seus olhos e bocas; e, "Voltarei e serei milhões", de Cantuária, retrata Marielle Franco sentada sobre uma pantera negra, empunhando uma lança fincada com a cabeça do atual governador do Rio de Janeiro, Wilson Witzel, são exemplos de como a arte contemporânea pode mobilizar valores fundamentais para o feminismo decolonial ao mesmo tempo em que fomenta resistência e promove denúncia.

Um dos méritos do livro é seu potencial didático. Ao reunir em português textos fundamentais para entender as contribuições da perspectiva decolonial para os estudos de gênero, o livro se torna uma interessante alternativa para fomentar o diálogo com pensadoras latino-americanas e africanas em cursos e disciplinas relacionadas aos estudos feministas. Outro elemento que merece destaque é a qualidade do projeto gráfico da edição. Pensamento Feminista Hoje: Perspectivas Decoloniais é um livro extremamente bem acabado com uma diagramação que torna a leitura agradável. O cuidado gráfico é especialmente relevante para a terceira parte do livro, que apresenta o trabalho das três artistas já mencionadas: Adriana Varejão, Rosana Paulino e Marcela Cantuária. A qualidade das reproduções das obras tem grande impacto na relação que constroem com os outros textos do livro.

Dessa forma, é uma obra extremamente necessária por reunir um conjunto de textos fundamentais para a compreensão do pensamento feminista latino-americano hoje. Trata-se, portanto, de um livro que aporta contribuições não apenas para os estudos de gênero e feministas, mas para qualquer exercício intelectual das humanidades que pretenda um olhar mais amplo para as mulheres do sul global.

\section{Referências}

HOLLANDA, Heloísa Buarque de (org.). Pensamento Feminista Hoje: Perspectivas Decoloniais. Rio de Janeiro: Bazar do Tempo, 2020.

HOLLANDA, Heloísa Buarque. "Introdução". In: HOLLANDA, Heloísa Buarque de (org.). Pensamento Feminista Hoje: Perspectivas Decoloniais. Rio de Janeiro: Bazar do Tempo, 2020. p. 11-34. 
Lívia Santos de Souza (42liviadesouza@gmail.com) é professora de espanhol e literaturas latino-americanas na Universidade Federal da Integração Latino-Americana (UNILA), atua no Programa de Pós-Graduação Interdisciplinar em Estudos Latino-Americanos. Desenvolve pesquisas nas áreas de estudos da tradução e literatura comparada com especial interesse na temática das comunidades latinas nos Estados Unidos.

\section{COMO CITAR ESSE ARTIGO DE ACORDO COM AS NORMAS DA REVISTA}

SOUZA, Lívia Santos de. "Sobre o feminismo decolonial". Revista Estudos Feministas, Florianópolis, v. 29, n. 1, e72726, 2021.

\section{CONTRIBUIÇÃO DE AUTORIA}

Não se aplica.

\section{FINANCIAMENTO}

Não se aplica.

\section{CONSENTIMENTO DE USO DE IMAGEM}

Não se aplica.

APROVAÇÃO DE COMITÊ DE ÉTICA EM PESQUISA

Não se aplica.

\section{CONFLITO DE INTERESSES}

Não se aplica.

\section{LICENÇA DE USO}

Este artigo está licenciado sob a Licença Creative Commons CC-BY International. Com essa licença você pode compartilhar, adaptar, criar para qualquer fim, desde que atribua a autoria da obra.

\section{HISTÓRICO}

Recebida em 03/04/2020

Reapresentada em 27/05/2020

Aprovada em 03/07/2020 